\title{
Expression of YKL-40 and MIP-1a proteins in exudates and transudates: biomarkers for differential diagnosis of pleural effusions? A pilot study
}

\author{
Tonia Adamidi ${ }^{1}$, Nikolaos Soulitzis²*, Eirini Neofytou², Savvas Zannetos ${ }^{3}$, Andreas Georgiou' ${ }^{1}$, Kleomenis Benidis ${ }^{1}$, \\ Alexis Papadopoulos ${ }^{1}$, Nikolaos M. Siafakas ${ }^{2,4}$ and Sophia E. Schiza ${ }^{2,4}$
}

\begin{abstract}
Background: YKL-40 is an extracellular matrix glycoprotein with a significant role in tissue inflammation and remodeling. MIP-1a has chemotactic and pro-inflammatory properties, and is induced by YKL-40 in several lung disorders. The aim of this study was to determine the levels of YKL-40 and MIP-1a in blood serum and pleural fluids of various pulmonary diseases, and to evaluate their potential role as differential diagnosis biomarkers.

Methods: We recruited 60 patients (age: $62.5 \pm 20.6$ years) with pleural effusions: 49 exudates and 11 transudates (T). Exudates were further classified based on the underlying disease: ten with tuberculosis (TB), 13 with lung cancer (LCa), 15 with metastatic cancer (MCa) of non-lung origin and 11 with parapneumonic (PN) effusions. YKL-40 and MIP1a levels were measured by ELISA.

Results: Pleural YKL-40 levels (ng/ml) were similar among all patient groups (TB: $399 \pm 36$, LCa: $401 \pm 112$, MCa: $416 \pm$ $34, \mathrm{PN}: 401 \pm 50, \mathrm{~T}: 399 \pm 42, p=0.92$ ). On the contrary, YKL-40 was significantly lower in the serum of TB patients (TB: $58 \pm 22$, LCa: $212 \pm 106$, MCa: $254 \pm 140$, PN: $265 \pm 140$, T: $229 \pm 123, p<0.001)$. Pleural MIP-1a protein levels (ng/ $\mathrm{ml}$ ) were statistically lower only in patients with LCa (TB: $25.0 \pm 20.2$, LCa: 7.3 \pm 6.0, MCa: $16.1 \pm 14.9$, PN: $25.4 \pm$ 27.9, T: $18.5 \pm 7.9, p=0.012$ ), a finding also observed in serum MIP-1a levels (TB: 17.1 \pm 7.6, LCa: 9.4 \pm 7.0, MCa: $28.7 \pm 28.7, \mathrm{PN}: 33.3 \pm 24.0, \mathrm{~T}: 22.9 \pm 8.7, p=0.003)$.

Conclusions: Our data suggest that both YKL-40 and MIP-1a, particularly in serum, could prove useful for the differentiation of pleural effusions in clinical practice, especially of TB or LCa origin. However, large-scale studies are needed to validate these findings.
\end{abstract}

Keywords: Tuberculosis, Lung cancer, Pneumonia, Metastatic cancer, Biomarkers

\section{Background}

Pleural effusion is the most common manifestation of pleural disease and can develop as a result of over 50 different pleuropulmonary or systemic disorders [1]. Although the annual incidence of pleural effusions is difficult to assess, since pleural effusions are usually the result of an underlying disease, there are an estimated 1.5 million cases per year in the United States alone [2].

\footnotetext{
* Correspondence: ngsoul@gmail.com

${ }^{2}$ Laboratory of Molecular and Cellular Pneumology, Medical School, University of Crete, Heraklion, Crete, Greece

Full list of author information is available at the end of the article
}

The most common causes for pleural effusions are congestive heart failure, infection (e.g., pneumonia), malignancy and pulmonary embolism. In general, the prevalence of pleural effusions in industrialized countries is approximately 320 cases per 100,000 residents, and is directly related to the prevalence of the underlying diseases [3]. For example, among countries with a high incidence of tuberculosis, the most frequent cause of pleural effusions is tuberculosis [4].

A major clinical challenge in the diagnosis and management of pleural effusions remains the differentiation between malignant and infectious effusions, using the 
right laboratory test leading to an accurate diagnosis, due to their different outcome and management [5]. Thus, the need for biomarkers that may help in this differentiation, in conjunction with the ones previously suggested by our group (IL-1A, IL-6, TNF) [6], is imperative.

The YKL-40 or Chitinase 3-like 1 protein is a growth factor for chondrocytes and fibroblasts. The precise role of this factor has not been clearly defined, but it seems that YKL-40 promotes fibroblast growth and is expressed by many cell types, such as synovial, smooth muscle cells, granulocytes, macrophages, liver and cancer cells, possessing a role in growth, tissue remodeling and inflammation [7]. YKL-40 levels increase during inflammation, since it plays an important role in chemiotaxis and in the accumulation and activation of cells associated with inflammation $[7,8]$. While high levels in serum and tissues have been observed in many lung diseases $[9,10]$, only three studies have assessed this factor as a diagnostic tool in pleural effusions [11-13].

Macrophage inflammatory protein (MIP-1a) is a cytokine belonging to the subgroup of CCL chemokines. Chemokines are low molecular weight proteins that act as mediators in chemotactic migration of leukocytes. The synthesis of chemokines is inducted by several cells after the activation of inflammation. CCL chemokines are chemotactic for mononuclear cells, neutrophils and other granulocytes. MIP-1a plays a significant role in the chemotactic activity of monocytes and of mononuclear phagocytes. In addition, MIP-1a has a different effect on chemotactic T-lymphocytes, natural killer cells, cytotoxic T-cells, B-cells, basophils and eosinophils. In general, MIP-1a is induced by YKL-40 in lung inflammatory diseases [10], and is expressed at the stages of both acute and chronic inflammation [14, 15]. However, few studies have examined the role of this protein in pleural effusions [16-18].

The purpose of this research was to measure YKL-40 and MIP-1a in conjunction, in both pleural fluids and in the serum of patients with well-defined causes of pleural effusion, in order to ascertain their use in the differential diagnosis among the underlying diseases.

\section{Methods}

\section{Study subjects}

This retrospective study involved 60 patients with pleural effusions [49 exudates (EX) and 11 transudates (T)] (Table 1) who were hospitalized in the Respiratory Medicine Clinic of the Nicosia General Hospital between November 2012 and October 2014. For patients with exudates, pleural effusions were either parapneumonic (PN: $n=11$ ) or were associated with tuberculosis (TB: $n=10$ ), and malignant effusions associated either with lung cancer (LCa: $n=13$ ) or with metastatic malignancies of non-lung origin (MCa: $n=15)$ (Table 2). The
Table 1 Clinical parameters and spirometric values of the exudates and transudates study groups

\begin{tabular}{llll}
\hline & Exudates $(n=49)$ & Transudates $(n=11)$ & $P$-Value \\
\hline Clinical parameters & & & \\
Gender & & & \\
$\quad$ Male & $33(67.3 \%)$ & $7(63.6 \%)$ & $1.00^{\mathrm{a}}$ \\
$\quad$ Female & $16(32.7 \%)$ & $4(36.4 \%)$ & \\
Age (mean \pm SD, years) & $60.1 \pm 20.9$ & $73.3 \pm 15.7$ & $0.055^{\mathrm{b}}$ \\
Smoking habit & & & \\
$\quad$ Current smokers & $19(38.8 \%)$ & $6(54.5 \%)$ & $0.55^{\mathrm{c}}$ \\
$\quad$ Non-smokers & $28(57.1 \%)$ & $5(45.5 \%)$ & \\
$\quad$ Ex-smokers & $2(4.1 \%)$ & $0(0.0 \%)$ & \\
Pack-years (mean \pm SD) & $55.2 \pm 36.8$ & $80.0 \pm 35.8$ & $0.17^{\mathrm{b}}$ \\
Spirometric values & & & \\
FEV $(\%$ pred.) & $79.8 \pm 18.0$ & $78.1 \pm 19.1$ & $0.78^{\mathrm{b}}$ \\
FVC (\% pred.) & $78.2 \pm 15.8$ & $76.0 \pm 16.7$ & $0.68^{\mathrm{b}}$ \\
FEV $/$ /FVC (\%) & $79.8 \pm 7.6$ & $76.7 \pm 10.1$ & $0.25^{\mathrm{b}}$ \\
\hline
\end{tabular}

${ }^{\mathrm{a}}$ Fisher's exact test; ${ }^{\mathrm{b}}$ Student's $t$-test; ${ }^{\mathrm{C}} \mathrm{Chi}$-square test

study protocol was approved by the Cyprus's National Bioethics Committee and the Research Ethics Committee of the Medical School, University of Crete. All participants completed and signed a consent form.

The determination of the etiology of pleural effusions was based on widely accepted criteria. The classification between exudates and transudates was based on Light's criteria [19], using serum and pleural fluid total protein and LDH measurements, and was further confirmed by the clinical diagnosis. Within exudates, PN effusions were characterized by coexistence of pneumonia, response to antibiotics and/or pleural fluid neutrophilia. Malignant effusions were diagnosed by cytological or histological examination. TB effusions were diagnosed with the presence of positive stain or culture for Mycobacterium tuberculosis in the pleural fluid, sputum or pleural biopsy, or with the presence of typical caseating granulomas in pleural biopsy, adenosine deaminase levels in pleural fluid greater than $40 \mathrm{U} / \mathrm{L}$ and response to antituberculous therapy.

\section{Sample collection and processing}

Samples were obtained during the first day of patient's hospitalization and from the first successful thoracentesis, before patients had received any treatment. Simultaneously, $10 \mathrm{~mL}$ of venous blood were obtained. Samples were analyzed for total and differential cell count, glucose, total protein, $\mathrm{LDH}$ and $\mathrm{pH}$. Additionally, cytological examinations and cultures for common pathogens and Mycobacterium tuberculosis were routinely performed in all pleural fluid samples. Aliquots of pleural fluid and blood samples were immediately centrifuged at $4000 \mathrm{~g}$ for $10 \mathrm{~min}$ at room 
Table 2 Clinical parameters among the four exudates subgroups

\begin{tabular}{|c|c|c|c|c|c|}
\hline & Tuberculosis $(n=10)$ & Lung Ca $(n=13)$ & Metastatic Ca $(n=15)$ & Parapneumonic effusions $(n=11)$ & $P$-value \\
\hline \multicolumn{6}{|l|}{ Gender } \\
\hline Male & $6(60.0 \%)$ & $11(84.6 \%)$ & $8(53.3 \%)$ & $8(72.7 \%)$ & \multirow[t]{2}{*}{$0.32^{a}$} \\
\hline Female & $4(40.0 \%)$ & $2(15.4 \%)$ & $7(46.7 \%)$ & $3(28.3 \%)$ & \\
\hline Age (mean $\pm S D$, years) & $27.1 \pm 5.2$ & $71.1 \pm 13.3$ & $70.4 \pm 11.3$ & $63.2 \pm 16.5$ & $<0.001^{b}$ \\
\hline \multicolumn{6}{|l|}{ Smoking habit } \\
\hline Current smokers & $0(0.0 \%)$ & $9(69.2 \%)$ & $5(33.3 \%)$ & $5(45.5 \%)$ & \multirow[t]{3}{*}{$0.023^{\mathrm{a}}$} \\
\hline Non-smokers & $10(100.0 \%)$ & $3(23.1 \%)$ & $9(60.0 \%)$ & $6(54.5 \%)$ & \\
\hline Ex-smokers & $0(0.0 \%)$ & 1 (7.7 \%) & $1(6.7 \%)$ & $0(0.0 \%)$ & \\
\hline Pack-years (mean \pm SD) & - & $57.5 \pm 29.6$ & $73.3 \pm 46.8$ & $29.0 \pm 26.6$ & $0.11^{\mathrm{b}}$ \\
\hline
\end{tabular}

${ }^{\mathrm{a}}$ Chi-square test; ${ }^{\mathrm{b}}$ Kruskal-Wallis $\mathrm{H}$ test

temperature and the supernatants were stored at $-80{ }^{\circ} \mathrm{C}$ until KKL-40 and MIP-1a protein measurements.

\section{ELISA detection}

Complying with the ERS Task Force guidelines regarding immunoassays [20], initial experiments were conducted, in order to verify the validity and reproducibility of the measurements. In all cases spike recovery was above the recommended $80 \%$, and therefore the assays could be safely used to determine the levels of the studied molecules. Subsequently, YKL-40 and MIP-1a protein levels were determined with the Human YKL-40 Platinum ELISA kit and Human MIP-1a Platinum ELISA kit, respectively (eBioscience Inc, San Diego, CA, USA). Plates were read on ELx808 ${ }^{\mathrm{TM}}$ Absorbance Microplate Reader (BioTek Instruments Inc, Winooski, VT, USA), at $450 \mathrm{~nm}$, using $630 \mathrm{~nm}$ as reference wavelength. Each sample was measured at least four times (two wells in two different assays) in order to minimize intra- and inter-assay variations. Samples' analysis was performed at the Molecular and Cellular Pulmonology Research Laboratory of the Medical School of the University of Crete.

\section{Statistical analysis}

Differences in YKL-40 and MIP-1a levels between our study groups were determined using Student's $t$-test, or its non-parametric equivalents Mann-Whitney $U$ and Kruskal-Wallis $\mathrm{H}$ tests. In case of a statistically significant result, a post hoc analysis was performed to determine the pairwise differences among the groups. Pearson's or the non-parametric Spearman's rank correlation was used to examine their association with continuous variables (age, pack-years, spirometric values, etc). Additionally, the $\chi^{2}$ test was used to examine their association with the various clinical parameters after stratification. Finally, univariate general linear model analysis, with age and smoking status as co-factors, was used in order to correct the results for the differences among the study groups.
For the evaluation of the diagnostic performance of YKL-40 and MIP-1a levels, Receiver Operator Characteristics (ROC) analysis was performed for all recognised significant differences among the groups. The Area under the Curve (AUC) was calculated with $95 \%$ Confidence Intervals (CIs). The optimal cut-off point was set as the value with the greatest sum of sensitivity and specificity. Consequently, sensitivity, specificity, Positive Likelihood Ratio (PLR), Negative Likelihood Ratio (NLR), Positive Predictive Value (PPV) and Negative Predictive Value (NPV) were calculated for each optimal point.

Statistical analyses were 2-sided and were performed with IBM SPSS Statistics v22.0 (IBM Corp, Armonk, NY, USA). Statistical significance was set at the $95 \%$ level $(P$ $<0.05)$. All data are presented as Mean \pm Standard Deviation (SD).

\section{Power and sample size calculations}

Power and sample size calculations were performed with the "PS Power and Sample Size Calculations" program (version 3.1.2) (http://biostat.mc.vanderbilt.edu/ wiki/Main/PowerSampleSize). For sample size calculations, power (type II error, or $\beta$ ) was set to $80 \%$ and statistical significance (type I error, or $\alpha$ ) was set to 0.05. For power calculations, size was set to 12 (for each exudates subgroup) and type I error was set to 0.05 . For both calculations, the meaningful differences in the mean value of YKL-40 and MIP-1a between the groups $(22 \mathrm{ng} / \mathrm{ml})$ and the maximum standard deviation (15) were used.

\section{Results}

\section{Clinical data analysis}

As seen in Table 1, there were no differences among the clinical or spirometric values between exudates and transudates. Additionally, there were also no significant differences in the clinical values among the 4 exudates 
subgroups, apart from the age $(p<0.001)$ and smoking status $(p=0.023)$ differentiation that the TB group displayed (Table 2).

\section{Exudates vs. Transudates}

No marked differences were observed in YKL-40 serum levels $(\mathrm{ng} / \mathrm{ml})$ between exudates and transudates (Ex: $188 \pm 137$ vs. T: $229 \pm 123, p=0.41$ ). A similar finding was measured in YKL-40 levels (ng/ ml) from pleural effusions (Ex: $404 \pm 59$ vs. T: $399 \pm$ $42, p=0.81$ ).

The same observations were made for MIP-1a serum (Ex: $22.2 \pm 20.9$ vs. T: $22.9 \pm 8.7, p=0.93$ ) and pleural effusions (Ex: $19.0 \pm 19.6$ vs. T: $18.5 \pm 7.9, p=0.94$ ) protein levels $(\mathrm{ng} / \mathrm{ml})$.

As expected, the pleural/serum ratio of both YKL-40 (Ex: 2.15, T: 1.75) and MIP-1a (Ex: 0.86, T: 0.81) were similar between the two study groups.

\section{Exudates subgroups}

However, when categorizing the heterogenic exudates subgroup, we found that although pleural YKL-40 levels $(\mathrm{ng} / \mathrm{ml})$ were similar among all patient groups (TB: $399 \pm 36$, LCa: $401 \pm 112$, MCa: $416 \pm 34$, PN: $401 \pm 50, p=0.85$ ) (Fig. 1b), YKL-40 was significantly lower in the serum of TB patients (TB: $58 \pm 22$, LCa: $212 \pm 106$, MCa: $254 \pm 140$, PN: $265 \pm 140$, T: $229 \pm 123$, $p<0.001$ ) (Fig. 1a). Subsequently, YKL-40 pleural/serum ratios were significantly higher in TB patients that in the other three exudates subgroups (TB: 6.93, LCa: 1.89, MCa: 1.64, PN: 1.52). Adenosine deaminase (ADA) levels were also high in TB patients ( $>40 \mathrm{U} / \mathrm{L})$. However, no correlation was found between YKL-40 serum or pleural levels with ADA expression, or with any other clinical parameters.

Because YKL-40 levels increase with age, and since TB patients were younger than the $\mathrm{LCa}, \mathrm{MCa}$ and $\mathrm{PN}$ subgroups and displayed different smoking habits, we performed univariate general linear model analysis using age and smoking status as co-factors, in order to exclude possible biases in our findings. Even after correction, YKL-40 levels were statistically significantly lower in the serum of TB patients when compared to $\mathrm{LCa}, \mathrm{MCa}$ and PN groups $(p=0.001)$.

Additionally, serum MIP-1a protein levels $(\mathrm{ng} / \mathrm{ml})$ were statistically lower only in patients with $\mathrm{LCa}$ (TB: $17.1 \pm 7.6$, LCa: $9.4 \pm 7.0$, MCa: $28.7 \pm 28.7, \mathrm{PN}$ : $33.3 \pm 24.0, p=0.008$ ) (Fig. 1c), a finding also observed in pleural MIP-1a levels (TB: $25.0 \pm 20.2$, LCa: $7.3 \pm 6.0$, MCa: $16.1 \pm 14.9$, PN: $25.4 \pm 27.9, \mathrm{~T}: 18.5 \pm$ 7.9, $p=0.019$ ) (Fig. 1d). Interestingly, the MIP-1a pleural/serum ratios were also different among the 4 exudates subgroups (TB: 1.47, LCa: 0.78, MCa: 0.56, PN: 0.76).
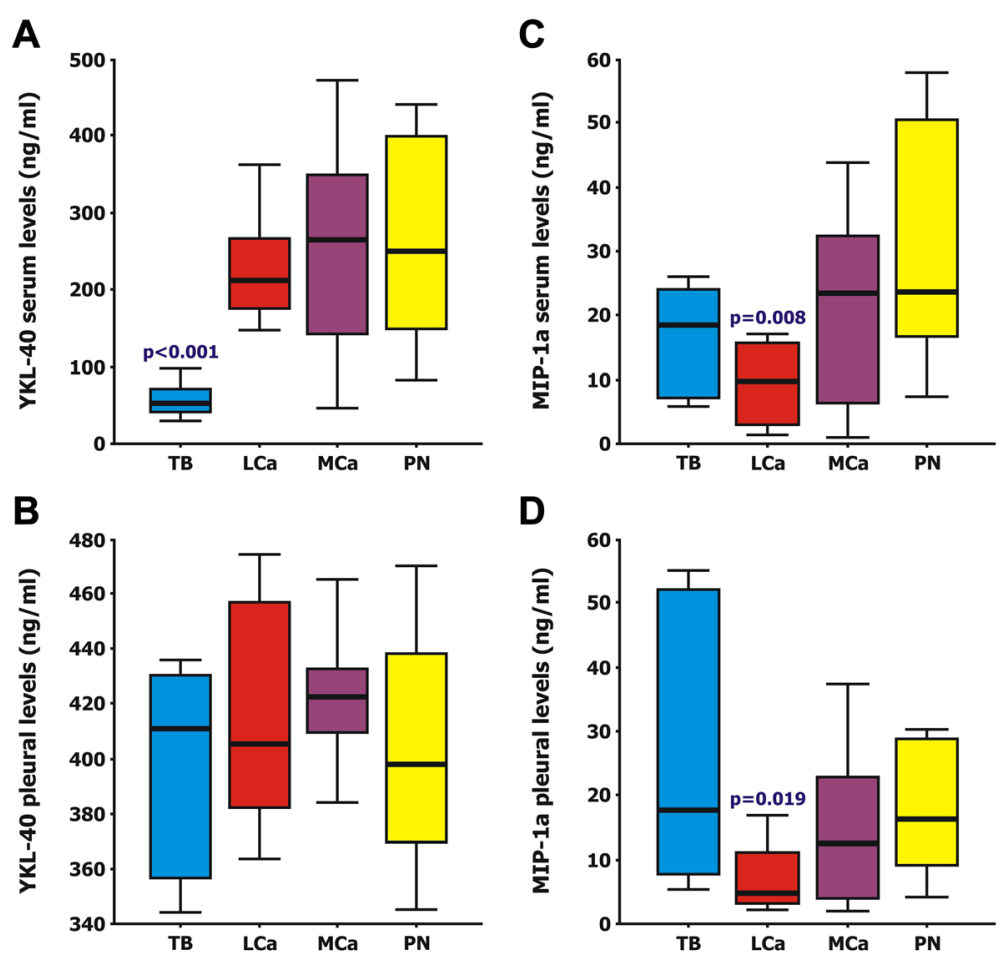

Fig. 1 Box and whisker plots depicting the protein levels of YKL-40 (a, b) and MIP-1a (c, d) in the serum $(\mathbf{a}, \mathbf{c})$ and pleural effusions (b, d) among the 4 exudates subgroups (TB: Tuberculosis; LCa: Lung Cancer; MCa: Metastatic Cancer of non-lung origin; PN: Parapneumonic effusions) 


\section{Sensitivity/Specificity calculations}

Using ROC analysis, we evaluated the diagnostic performance of both YKL-40 and MIP-1a proteins (Table 3). YKL-40 serum levels appear to be an excellent marker for the differentiation of tuberculosis from the other exudates. Using a cut-off point of 122.8, 118.9 and $113.2 \mathrm{ng} / \mathrm{ml}$, it represents $91 \%$ sensitivity and $100 \%$ specificity for the differentiation between TB and LCa, $\mathrm{TB}$ and $\mathrm{MCa}$, and $\mathrm{TB}$ and $\mathrm{PN}$ effusions, respectively (Table 3A, Fig. 2a).

MIP-1a serum levels $(\mathrm{ng} / \mathrm{ml})$ also distinguish $\mathrm{LCa}$ from the other exudates subgroups (Table 3B, Fig. 2b). For a cut-off point of $22.5 \mathrm{ng} / \mathrm{ml}$, sensitivity is at $100 \%$ and specificity at $70 \%$, for the differentiation of $\mathrm{LCa}$ from TB. In addition, using a cut-off point of $19.8 \mathrm{ng} / \mathrm{ml}$, sensitivity is at $67 \%$ and specificity at $100 \%$, for the differentiation of LCa and MCa. Finally, using a cut-off of $19.4 \mathrm{ng} / \mathrm{ml}$, sensitivity is at $80 \%$ and specificity at $100 \%$, for the differentiation of LCa from PN effusions. Similar results were obtained from MIP-1a pleural levels (Table 3C, Fig. 2c).

\section{Power calculations}

According to power and sample size calculations, our study had $83.4 \%$ power to find the statistically significant associations that were observed. Interestingly, only 12 samples on average of each exudates category were needed in order for our study to have at least $80 \%$ power.

\section{Discussion}

In the present study we measured the protein levels of YKL-40 and MIP-1a in pleural fluids, in order to demonstrate the correlation with their circulating levels in peripheral blood, and to determine the diagnostic value of these molecules in the differential diagnosis of pleural effusions, especially between pleural effusions associated with lung cancer and tuberculosis.

The levels of YKL-40 in pleural effusions were similar among all examined groups, without any statistical differences between them. On the contrary, YKL-40 values in the peripheral blood of patients with tuberculosis were statistical significantly lower in comparison with all the other patient categories, even after age correction. YKL-40 is expressed in the lung and serum of patients with bronchial asthma, chronic obstructive pulmonary disease, pulmonary fibrosis, sarcoidosis, lung cancer, respiratory infections, tuberculosis and cystic fibrosis [21-24].

The biological activity of YKL-40 is still largely unknown, and although a specific cell receptor for YKL-40 has not yet been found, it seems to be associated with collagen type I, II and III [25]. YKL-40 activates intracellular pathways through the cell membrane [7, 8], while acting like chitin sensor directing the macrophages and activating the anti-inflammatory response to infection [26]. Additionally, YKL-40 promotes the migration of endothelial cells and contributes to the diversification of the morphology of the endothelium. It is also found in special granules of neutrophil and mast cells [8, 27]. Nevertheless, YKL-40 inhibits oxidative damage in the lung and increases the Th2 immune response, regulates apoptosis, activates macrophages and contributes to fibrosis and rehabilitation of tissue injury $[28,29]$. The expression of YKL-40 seems to be affected by IFN- $\gamma$, an important cytokine to Th1 immune response [7], while

Table 3 Diagnostic performance of (A) YKL-40 serum levels $(\mathrm{ng} / \mathrm{ml})$ for the differential diagnosis of Tuberculosis, (B) MIP-1a Serum levels $(\mathrm{ng} / \mathrm{ml})$ and (C) MIP-1a Pleural levels $(\mathrm{ng} / \mathrm{ml})$ for the differential diagnosis of Lung Cancer, at the optimal cut-off points of the ROC analysis

\begin{tabular}{|c|c|c|c|c|c|c|c|c|c|}
\hline & Optimal cut off point & Sensitivity (\%) & Specificity (\%) & $+\mathrm{LR}$ & $-L R$ & PPV (\%) & NPV (\%) & $A \cup C$ & $95 \% \mathrm{Cls}$ \\
\hline \multicolumn{10}{|c|}{ A. YKL-40 Serum levels (ng/ml) } \\
\hline TB vs LCa & 122.8 & 90.9 & 100.0 & $>20.0$ & 0.09 & 100.0 & 85.7 & 0.857 & $0.598-1.000$ \\
\hline TB vs MCa & 118.9 & 90.9 & 100.0 & $>20.0$ & 0.09 & 100.0 & 87.5 & 0.913 & $0.745-1.000$ \\
\hline TB vs PN & 113.2 & 90.9 & 100.0 & $>20.0$ & 0.09 & 100.0 & 87.5 & 0.975 & $0.913-1.000$ \\
\hline \multicolumn{10}{|c|}{ B. MIP-1a Serum levels (ng/ml) } \\
\hline LCa vs TB & 22.5 & 100.0 & 70.0 & 3.3 & $>20.0$ & 100.0 & 30.0 & 0.850 & $0.667-1.000$ \\
\hline LCa vs MCa & 19.8 & 66.7 & 100.0 & $>20.0$ & 0.33 & 100.0 & 60.0 & 0.731 & $0.488-0.975$ \\
\hline LCa vs PN & 19.4 & 80.0 & 100.0 & $>20.0$ & 0.20 & 100.0 & 75.0 & 0.875 & $0.694-1.000$ \\
\hline \multicolumn{10}{|c|}{ C. MIP-1a Pleural levels (ng/ml) } \\
\hline LCa vs TB & 17.0 & 100.0 & 60.0 & 2.5 & $>20.0$ & 100.0 & 60.0 & 0.857 & $0.676-1.000$ \\
\hline LCa vs MCa & 3.8 & 57.1 & 80.0 & 2.9 & 1.9 & 57.1 & 80.0 & 0.679 & $0.418-0.939$ \\
\hline LCa vs PN & 8.2 & 71.4 & 87.5 & 5.7 & 3.1 & 71.4 & 87.5 & 0.839 & $0.630-1.000$ \\
\hline
\end{tabular}




\section{A TB vs. LCa (AUC $=0.857)$}

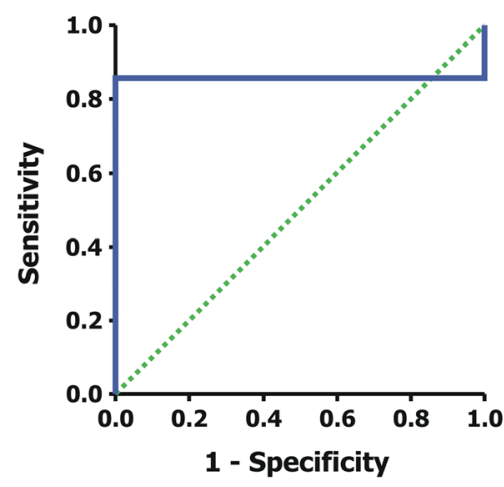

B

LCa vs. TB (AUC $=0.850)$

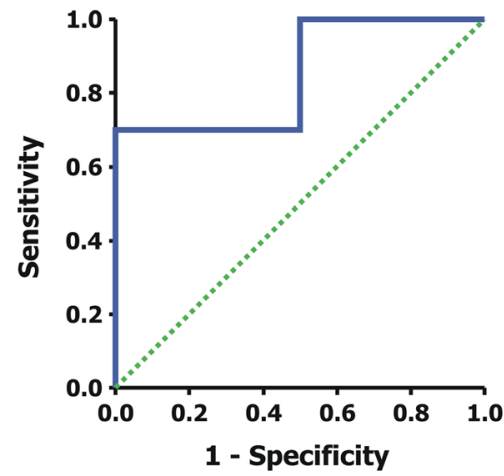

C

LCa vs. TB $(A \cup C=0.857)$

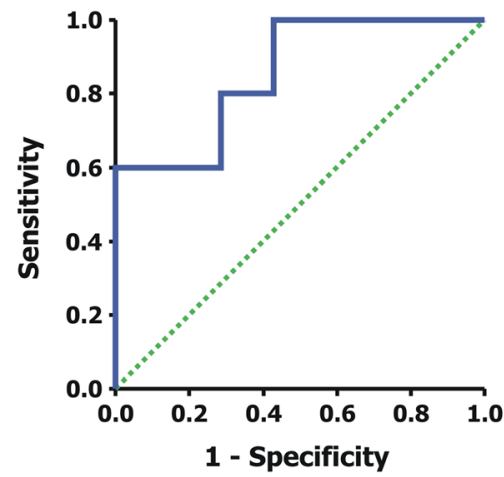

TB vs. $\mathrm{MCa}(\mathrm{AUC}=0.913)$

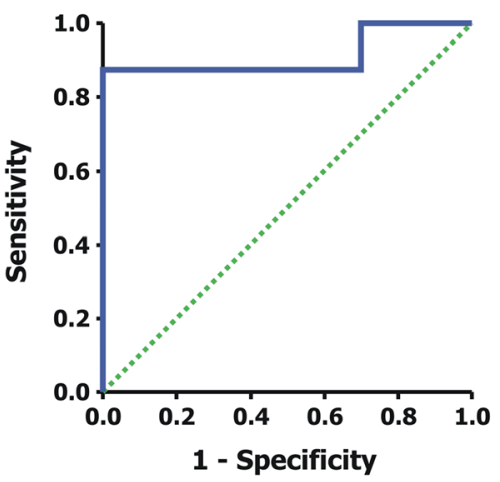

LCa vs. $\mathrm{MCa}(\mathrm{AUC}=0.731)$

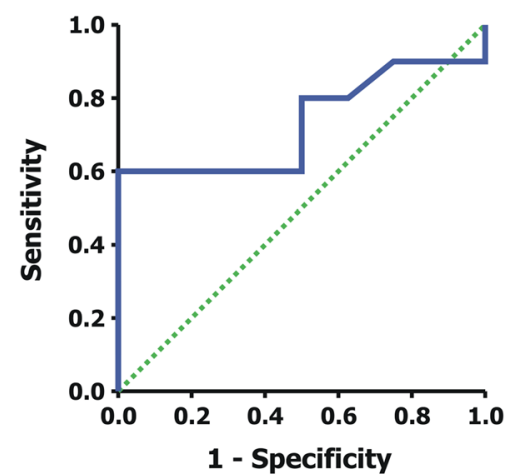

LCa vs. MCa $(A \cup C=0.679)$

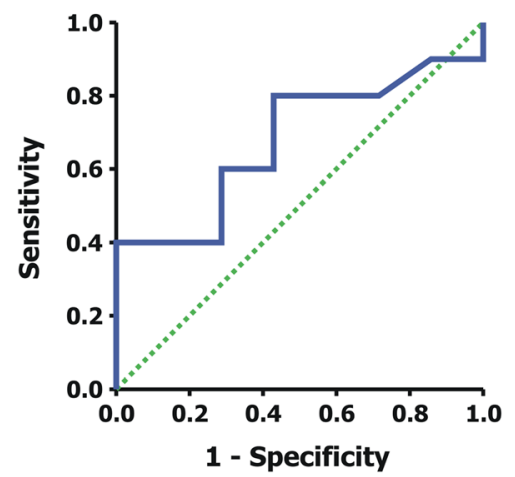

TB vs. PN (AUC $=0.975)$

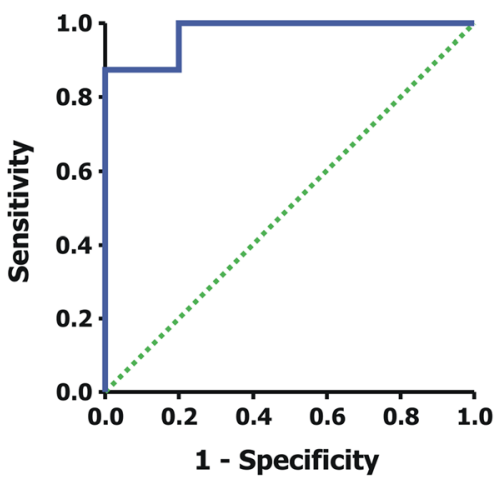

LCa vs. PN (AUC=0.875)

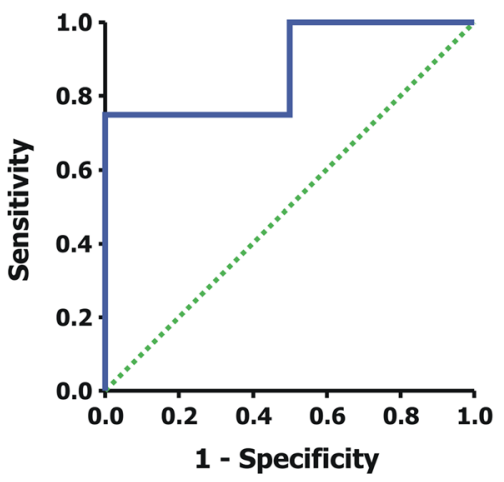

LCa vs. PN (AUC $=0.839)$

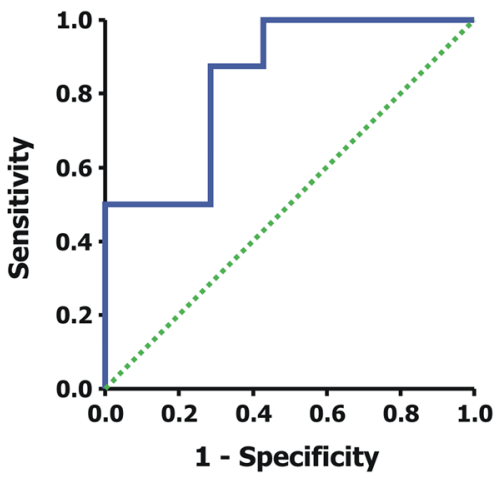

Fig. 2 Receiver operator characteristic (ROC) analysis curves, depicting the specificity and the sensitivity of YKL-40 and MIP-1a between our study groups: a ROC curves of YKL-40 serum levels for the differentiation of TB vs. LCa, TB vs. MCa and TB vs. PN, respectively. $\mathbf{b}$ ROC curves of MIP-1a serum levels for the differentiation of LCa vs. TB, LCa vs. MCa and LCa vs. PN, respectively. c ROC curves of MIP-1a pleural levels for the differentiation of LCa vs. TB, LCa vs. MCa and LCa vs. PN, respectively. TB: Tuberculosis; LCa: Lung Cancer; MCa: Metastatic Cancer of non-lung origin; PN: Parapneumonic effusions

it is also activated from cytokines IL-6, IL-13, IL-17 and IL-18, which play an important role in inflammation $[7,29]$.

YKL-40 has not been extensively studied in pleural effusions. Kim et al measured the levels of YKL-40 in pleural fluid and serum of patients with tuberculosis, malignant effusions, parapneumonic effusions and transudates due to congestive heart failure [11]. Their results suggest that YKL-40 levels were higher in pleural fluids from exudates versus transudates. A similar finding was 
reported by Kayhan et al [12]. Both studies are not in accordance with our observations, in which YKL-40 levels were similar in both exudates and transudates. The high levels of YKL-40 in our transudates could be attributed to the existence of fluid in interstitial lung space, to the increased pressure in the pleural capillaries and to endothelial vessel damage, factors that can lead to increasing levels of YKL-40 [7]. In addition, patients in our study with congestive heart failure and transudates had a considerable amount of co-morbidities, such as atherosclerotic coronary artery disease, type II diabetes and smoking habit, which can also contribute to the increasing levels of YKL-40 [10, 22, 30, 31].

Moreover, in the study by Kim et al, YKL-40 levels were higher in pleural fluids from tuberculous pleural effusions and lower in malignant effusions [11]. In the present study the levels of YKL-40 in pleural fluids were similar among tuberculosis, lung cancer and metastatic cancer of non-lung origin. Our study, however, agrees with Kim et al study's findings regarding the ratio of YKL-40 in tuberculous pleural fluid compared to that of the serum, since in both studies this percentage was higher than in the other groups [11]. This observation accounts for an important finding of our study, given that it differentiates tuberculous pleural effusions from the other exudates subgroups, with high sensitivity $(91 \%)$ and specificity (100\%), despite the significant age difference of TB patients. Although recent studies have shown that YKL-40 serum levels could be utilized in the diagnosis of endometrial carcinoma (with $74 \%$ sensitivity and $87 \%$ specificity) [32], and of esophageal squamous cell carcinomas (with $73 \%$ sensitivity and $84 \%$ specificity) [33], or could provide information regarding the response to chemotherapy and overall survival in patients with small cell lung cancer [34], this research provides evidence for the first time that YKL-40 could also be used for the differential diagnosis of tuberculosis from other pleural effusions.

The diagnostic performance of YKL-40, in comparison to already established markers like $\mathrm{C}$-reactive protein (CRP) and ADA, is extremely promising. CRP had $100 \%$ sensitivity and only $46 \%$ specificity when distinguishing TB from malignant effusions [35], while in another study its sensitivity was $74 \%$ and its specificity $77 \%$, respectively [36], findings that were verified by a third study, in which CRP performed poorly $(\mathrm{AUC}=0.57$ vs. 0.86 for YKL-40 in ours) and only ADA performed extremely well (AUC = 0.94) [37]. Another study, in which ADA levels were utilized to distinguish tuberculous from malignant effusions, had $89 \%$ sensitivity and $70 \%$ specificity [38], while two more studies in which TB was compared to effusions of all other origins, ADA had 87$88 \%$ sensitivity and $92 \%$ specificity $[39,40]$. Based on the above, we can deduce that YKL-40 is superior as a diagnostic marker in distinguishing tuberculous from malignant effusions than CRP, and that is has a similar if not a better performance when compared to ADA.

Yu et al have shown that the immunological environment of a tuberculous pleural effusion is characterized by distinct biomarkers and in different concentrations in comparison with the serum [17]. CCL1, CCL21 factors and IL- 6 are also elevated in tuberculous pleural effusions and have a specific antigenic reaction in their expression. Following the antigenic stimulation from the Mycobacterium tuberculosis, these factors are secreted in large amounts from the mononuclear cells of pleural fluid, activating YKL-40.

The anti-inflammatory protein of macrophage MIP-1a (CCL3) belongs to the cytokines family and in the subgroup of MIP-1 CC chemokines [41]. MIP-1 chemokines are produced by many cells, especially from $\mathrm{T}$ and $\mathrm{B}$ lymphocytes, neutrophils, dendritic cells, osteoblasts, astrocytes, epithelial cells of the lower airways, alveolar macrophages, eosinophils, fibroblasts and natural killer cells. The production of MIP-1 is caused by various proinflammatory factors and cytokines, such as viral infection, Gram positive bacteria, TNF-a, IFN- $\gamma$, IFN7, IL-1 $\alpha / \beta$, IL-13 and many others $[16,41,42]$. MIP- 1 chemokines act through surface receptors and while having strong chemotactic action, they play a significant action in the activation of inflammation and hemostasis [41]. Their actions include target cells via chemotaxis, degranulation, phagocytosis and mediator synthesis [41, 42]. MIP1 chemokines play an important role in both acute and chronic inflammation, primarily with the recruitment of proinflammatory cells. Their role is particularly important in chemotaxis of $\mathrm{T}$ lymphocytes in the inflammatory tissues, but also in the migration of monocytes, dendritic cells and natural killer cells [42]:It seems that this group of chemokines, and especially MCP-1 (CCL2) whose levels increase significantly in malignant pleural effusions [16, 43-46], plays an important role in inflammatory lung diseases such as asthma, sarcoidosis, pulmonary fibrosis, but also in tuberculosis, pleural effusions, pneumonia, acute espiratory distress syndrome (ARDS) and tumors development [42, 47-49].

In our study, MIP-1a protein levels were high in all patient groups, both in the pleural fluid and the peripheral blood, with the exception of patients with malignant effusions associated with lung cancer. Their values were statistically significant lower in comparison with all the other categories (tuberculous, parapneumonic, transudates and malignant effusions associated with metastatic cancer of non-lung origin), both in the pleural fluid and the peripheral blood. In the study by Mohammed et al, the levels of MIP-1a were elevated in patients with complicated and non-complicated parapneumonic pleural effusions, while they were low in malignant pleural 
effusions and even lower in transudates associated with congestive heart failure [16]. According to that study, the chemotactic activity of MIP-1a was reduced in malignant pleural effusions compared with parapneumonic pleural effusions. In another study by Yuan et al, MIP-1a along with its receptor CCR1, facilitate the migration of malignant hepatoma cells through $\mathrm{Ca}^{2+}$ ion channels, thus playing a significant role in hepatocellular carcinoma invasion and metastasis [50]. These findings are in accordance with ours, since MIP-1a levels were higher in effusions associated with metastatic cancers of nonlung origin, compared to effusions associated with lung cancer. Our findings also suggest that MIP-1a could also be used for the differential diagnosis of lung cancer from tuberculosis (sensitivity $100 \%$ /specificity $70 \%$ ), from parapneumonic effusions (sensitivity $80 \%$ /specificity $100 \%$ ) and especially from metastatic tumors of non-lung origin (sensitivity $67 \%$ /specificity $100 \%$ ), which are more difficult to distinguish. MIP-1a has not been widely used for diagnostic purposes, apart from malignant gliomas, in which MIP-1a levels provided $100 \%$ sensitivity and $88 \%$ specificity for the diagnosis of this tumor type versus controls [51].

YKL-40 and MIP-1a belong to the same biochemical pathway, and MIP-1a is induced by YKL-40 in lung inflammatory diseases. Letuve et al demonstrated that YKL-40 causes the release of three chemokines from the alveolar macrophages of smokers with or without chronic obstructive pulmonary disease (COPD). Precisely IL-8, MCP-1 and MIP-1a seem to be associated with the pathogenesis of COPD through tissue inflammation and fibrosis [10]. In the study of Sutherland et $a l$, the researchers observed the inhibitory action of acidic mammalian chitinase (AMC) in the recruitment of neutrophils through MIP-1a action. They speculated that AMC and chitinase like proteins (CLP), which YKL-40 is a member of, have cross-regulatory actions. The increased expression of CLPs leads to neutrophils recruitment and causes increased secretion of MIP-1a [52].

\section{Conclusion}

The present study measured for the first time the protein levels of YKL-40 factor in combination with the MIP-1a chemokine, both in serum and pleural fluid, exhibiting their diagnostic value in the differential diagnosis of pleural effusions. YKL-40 levels were reduced in the serum of patients with tuberculous pleurisy versus patients with malignant effusions associated with lung cancer, parapneumonic effusions, transudates and malignant effusions associated with metastatic cancer of nonlung origin. MIP-1a levels were lower both in serum and pleural fluid of patients with malignant effusions associated with lung cancer. Our results suggest that these markers could be used for the differentiation of infectious and malignant effusions in clinical practice. They could improve the differential diagnosis between the two major causes of lymphocyte-dominant pleural effusions, i.e. tuberculosis and lung cancer, and in relation to other causes of pleural effusions. Moreover, these measurements, in conjunction with other tests, could allow for the differential diagnosis between a malignant pleural effusion associated with lung cancer and a malignant effusion associated with metastatic cancer of non-lung origin.

\section{Competing interest}

The authors declare that they have no conflict of interests.

\section{Authors' contribution}

TA and NMS conceived the study and participated in its design along with NS, EN and AG. Data acquisition was performed by NS, EN, KB and AP. Data was analyzed by NS and SZ and interpreted by NS, NMS and SES. TA and NS drafted the manuscript, which was revised by TA, NS, NMS and SES. All authors read and approved the final manuscript.

\section{Author details}

'Department of Thoracic Medicine, Nicosia General Hospital, Nicosia, Cyprus. ¿Laboratory of Molecular and Cellular Pneumology, Medical School, University of Crete, Heraklion, Crete, Greece. ${ }^{3}$ Department of HealthCare Management, Open University of Cyprus, Nicosia, Cyprus. ${ }^{4}$ Department of Thoracic Medicine, University Hospital of Heraklion, Heraklion, Crete, Greece.

Received: 8 July 2015 Accepted: 18 November 2015

Published online: 01 December 2015

\section{References}

1. Cohen M, Sahn SA. Resolution of pleural effusions. Chest. 2001;119(5):1547-62.

2. Sahn SA. The value of pleural fluid analysis. Am J Med Sci. 2008;335(1):7-15.

3. Sahn SA. Pleural effusions of extravascular origin. Clin Chest Med. 2006;27(2): 285-308.

4. Liam CK, Lim KH, Wong CM. Causes of pleural exudates in a region with a high incidence of tuberculosis. Respirology. 2000;5(1):33-8.

5. Marel M, Stastny B, Melinova L, Svandova E, Light RW. Diagnosis of pleural effusions. Experience with clinical studies, 1986 to 1990. Chest. 1995;107(6): 1598-603.

6. Xirouchaki N, Tzanakis N, Bouros D, Kyriakou D, Karkavitsas N, Alexandrakis $M$, et al. Diagnostic value of interleukin-1alpha, interleukin-6, and tumor necrosis factor in pleural effusions. Chest. 2002;121(3):815-20.

7. Kazakova MH, Sarafian VS. YKL-40 - a novel biomarker in clinical practice? Folia Med (Plovdiv). 2009:51(1):5-14.

8. Volck B, Price PA, Johansen JS, Sorensen O, Benfield TL, Nielsen HJ, et al. YKL-40, a mammalian member of the chitinase family, is a matrix protein of specific granules in human neutrophils. Proc Assoc Am Physicians. 1998; 110(4):351-60.

9. Chupp GL, Lee CG, Jarjour N, Shim YM, Holm CT, He S, et al. A chitinase-like protein in the lung and circulation of patients with severe asthma. N Engl J Med. 2007:357(20):2016-27

10. Letuve S, Kozhich A, Arouche N, Grandsaigne M, Reed J, Dombret MC, et al. YKL-40 is elevated in patients with chronic obstructive pulmonary disease and activates alveolar macrophages. J Immunol. 2008;181(7):5167-73.

11. Kim HR, Jun CD, Lee KS, Cho JH, Jeong ET, Yang SH, et al. Levels of YKL-40 in pleural effusions and blood from patients with pulmonary or pleural disease. Cytokine. 2012;58(3):336-43.

12. Kayhan S, Gumus A, Cinarka H, Murat N, Yilmaz A, Bedir R, et al. The clinical utility of pleural YKL-40 levels in diagnosing pleural effusions. J Thorac Dis. 2013:5(5):634-40.

13. Attia A, Rasmy A, Amin A, Alanazi M. Evaluation of pleural fluid YKL-40 as a marker of malignant pleural effusion. Egypt J Chest Dis Tuberc. 2015;64(2): 489-95.

14. Schall TJ. Biology of the RANTES/SIS cytokine family. Cytokine. 1991;3(3): 165-83. 
15. Taub DD, Conlon K, Lloyd AR, Oppenheim JJ, Kelvin DJ. Preferential migration of activated CD4+ and CD8+ T cells in response to MIP-1 alpha and MIP-1 beta. Science. 1993;260(5106):355-8

16. Mohammed KA, Nasreen N, Ward MJ, Antony VB. Macrophage inflammatory protein-1alpha C-C chemokine in parapneumonic pleural effusions. J Lab Clin Med. 1998;132(3):202-9.

17. Yu Y, Zhang Y, Hu S, Jin D, Chen X, Jin Q, et al. Different patterns of cytokines and chemokines combined with IFN-gamma production reflect Mycobacterium tuberculosis infection and disease. PLoS ONE. 2012;7(9), e44944.

18. Yang CS, Lee JS, Lee HM, Shim TS, Son JW, Jung SS, et al. Differential cytokine levels and immunoreactivities against Mycobacterium tuberculosi antigens between tuberculous and malignant effusions. Respir Med. 2008; 102(2):280-6.

19. Light RW, Macgregor MI, Luchsinger PC, Ball Jr WC. Pleural effusions: the diagnostic separation of transudates and exudates. Ann Intern Med. 1972; 77(4):507-13.

20. Kelly MM, Keatings V, Leigh R, Peterson C, Shute J, Venge P, et al. Analysis of fluid-phase mediators. Eur Respir J Suppl. 2002;37:24s-39.

21. Johansen JS, Drivsholm L, Price PA, Christensen IJ. High serum YKL-40 level in patients with small cell lung cancer is related to early death. Lung Cancer. 2004;46(3):333-40.

22. Otsuka K, Matsumoto H, Niimi A, Muro S, Ito I, Takeda T, et al. Sputum YKL40 levels and pathophysiology of asthma and chronic obstructive pulmonary disease. Respiration. 2012;83(6):507-19.

23. Furuhashi K, Suda T, Nakamura Y, Inui N, Hashimoto D, Miwa S, et al. Increased expression of YKL-40, a chitinase-like protein, in serum and lung of patients with idiopathic pulmonary fibrosis. Respir Med. 2010;104(8): 1204-10.

24. Kruit A, Grutters JC, Ruven HJ, van Moorsel CC, van den Bosch JM. A CHI3L1 gene polymorphism is associated with serum levels of YKL-40, a novel sarcoidosis marker. Respir Med. 2007;101(7):1563-71.

25. Bigg HF, Wait R, Rowan AD, Cawston TE. The mammalian chitinase-like lectin, YKL-40, binds specifically to type I collagen and modulates the rate of type I collagen fibril formation. J Biol Chem. 2006;281(30):21082-95.

26. Renkema GH, Boot RG, Au FL, Donker-Koopman WE, Strijland A, Muijsers $\mathrm{AO}$, et al. Chitotriosidase, a chitinase, and the 39-kDa human cartilage glycoprotein, a chitin-binding lectin, are homologues of family 18 glycosyl hydrolases secreted by human macrophages. Eur J Biochem. 1998;251(1-2): 504-9.

27. Ringsholt M, Hogdall EV, Johansen JS, Price PA, Christensen LH. YKL-40 protein expression in normal adult human tissues - an immunohistochemical study. J Mol Histol. 2007:38(1):33-43

28. Lee CG, Da Silva CA, Dela Cruz CS, Ahangari F, Ma B, Kang MJ, et al. Role of chitin and chitinase/chitinase-like proteins in inflammation, tissue remodeling, and injury. Annu Rev Physiol. 2011;73:479-501.

29. Zhu Z, Zheng T, Homer RJ, Kim YK, Chen NY, Cohn L, et al. Acidic mammalian chitinase in asthmatic Th2 inflammation and IL-13 pathway activation. Science. 2004;304(5677):1678-82.

30. Rathcke CN, Johansen JS, Vestergaard H. YKL-40, a biomarker of inflammation, is elevated in patients with type 2 diabetes and is related to insulin resistance. Inflamm Res. 2006;55(2):53-9.

31. Wang Y, Ripa RS, Johansen JS, Gabrielsen A, Steinbruchel DA, Friis T, et al. YKL-40 a new biomarker in patients with acute coronary syndrome or stable coronary artery disease. Scand Cardiovasc J. 2008;42(5):295-302.

32. Cheng $D$, Sun $Y$, He H. Diagnostic role of circulating YKL-40 in endometrial carcinoma patients: a meta-analysis of seven related studies. Med Oncol. 2014;31(12):326.

33. Zheng X, Xing S, Liu XM, Liu W, Liu D, Chi PD, et al. Establishment of using serum YKL-40 and SCCA in combination for the diagnosis of patients with esophageal squamous cell carcinoma. BMC Cancer. 2014;14:490.

34. Xu CH, Yu LK, Hao KK. Serum YKL-40 level is associated with the chemotherapy response and prognosis of patients with small cell lung cancer. PLOS ONE. 2014:9(5), e96384.

35. Kiropoulos TS, Kostikas K, Oikonomidi S, Tsilioni I, Nikoulis D, Germenis A, et al. Acute phase markers for the differentiation of infectious and malignant pleural effusions. Respir Med. 2007;101(5):910-8.

36. Porcel JM, Vives M, Cao G, Bielsa S, Ruiz-Gonzalez A, Martinez-lribarren A, et al. Biomarkers of infection for the differential diagnosis of pleural effusions. Eur Respir J. 2009:34(6):1383-9.
37. Daniil ZD, Zintzaras E, Kiropoulos T, Papaioannou Al, Koutsokera A, Kastanis $A$, et al. Discrimination of exudative pleural effusions based on multiple biological parameters. Eur Respir J. 2007;30(5):957-64

38. Zaric B, Kuruc V, Milovancev A, Markovic M, Sarcev T, Canak V, et al. Differential diagnosis of tuberculous and malignant pleural effusions: what is the role of adenosine deaminase? Lung. 2008:186(4):233-40.

39. Perez-Rodriguez E, Perez Walton IJ, Sanchez Hernandez JJ, Pallares E, Rubi J, Jimenez Castro D, et al. ADA1/ADAp ratio in pleural tuberculosis: an excellent diagnostic parameter in pleural fluid. Respir Med. 1999;93(11):816-21.

40. Chen ML, Yu WC, Lam CW, Au KM, Kong FY, Chan AY. Diagnostic value of pleural fluid adenosine deaminase activity in tuberculous pleurisy. Clin Chim Acta. 2004;341(1-2):101-7.

41. Maurer M, von Stebut E. Macrophage inflammatory protein-1. Int J Biochem Cell Biol. 2004;36(10):1882-6.

42. Menten P, Wuyts A, Van Damme J. Macrophage inflammatory protein-1. Cytokine Growth Factor Rev. 2002;13(6):455-81.

43. Craig MJ, Loberg RD. CCL2 (Monocyte Chemoattractant Protein-1) in cancer bone metastases. Cancer Metastasis Rev. 2006;25(4):611-9.

44. Atanackovic D, Cao Y, Kim JW, Brandl S, Thom I, Faltz C, et al. The loca cytokine and chemokine milieu within malignant effusions. Tumour Biol. 2008:29(2):93-104

45. Soria G, Yaal-Hahoshen N, Azenshtein E, Shina S, Leider-Trejo L, Ryvo L, et al. Concomitant expression of the chemokines RANTES and MCP-1 in human breast cancer: a basis for tumor-promoting interactions. Cytokine. 2008; 44(1):191-200

46. Yoshimura T, Howard OM, Ito T, Kuwabara M, Matsukawa A, Chen K, et al. Monocyte chemoattractant protein-1/CCL2 produced by stromal cells promotes lung metastasis of $4 \mathrm{~T} 1$ murine breast cancer cells. PLOS ONE. 2013;8(3), e58791.

47. Holgate ST, Bodey KS, Janezic A, Frew AJ, Kaplan AP, Teran LM. Release of RANTES, MIP-1 alpha, and MCP-1 into asthmatic airways following endobronchial allergen challenge. Am J Respir Crit Care Med. 1997; 156(5):1377-83.

48. Ziegenhagen MW, Schrum S, Zissel G, Zipfel PF, Schlaak M, Muller-Quernheim J. Increased expression of proinflammatory chemokines in bronchoalveolar lavage cells of patients with progressing idiopathic pulmonary fibrosis and sarcoidosis. J Investig Med. 1998;46(5):223-31.

49. Goodman RB, Strieter RM, Martin DP, Steinberg KP, Milberg JA, Maunder RJ, et al. Inflammatory cytokines in patients with persistence of the acute respiratory distress syndrome. Am J Respir Crit Care Med. 1996;154(3 Pt 1): $602-11$.

50. Yuan Y, Liu J, Liu Z, He Y, Zhang Z, Jiang C, et al. Chemokine CCL3 facilitates the migration of hepatoma cells by changing the concentration intracellular Ca. Hepatol Res. 2010;40(4):424-31.

51. Xu BJ, An QA, Srinivasa Gowda S, Yan W, Pierce LA, Abel TW, et al. Identification of blood protein biomarkers that aid in the clinical assessment of patients with malignant glioma. Int J Oncol. 2012;40(6):1995-2003.

52. Sutherland TE, Andersen OA, Betou M, Eggleston IM, Maizels RM, van Aalten $D$, et al. Analyzing airway inflammation with chemical biology: dissection of acidic mammalian chitinase function with a selective drug-like inhibitor. Chem Biol. 2011;18(5):569-79.

\section{Submit your next manuscript to BioMed Central and we will help you at every step:}

- We accept pre-submission inquiries

- Our selector tool helps you to find the most relevant journal

- We provide round the clock customer support

- Convenient online submission

- Thorough peer review

- Inclusion in PubMed and all major indexing services

- Maximum visibility for your research

Submit your manuscript at www.biomedcentral.com/submit
C) BioMed Central 